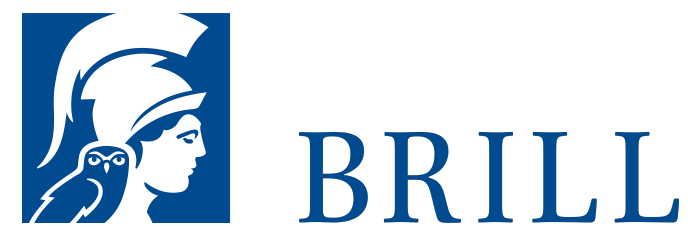

\title{
Die politische Philosophie von Amartya Sen
}

Soziale Gerechtigkeit und globale Entwicklung auf Grundlage des Capability Approach

Author: Julian Molina Romero

\section{Blick ins Buch}

Was genau verlangt soziale Gerechtigkeit? Diese Frage hat immer schon zu großen Meinungsdifferenzen geführt, sowohl in der politischen Rhetorik als auch in der politischen Philosophie. Neben John Rawls' bahnbrechender Theorie der Gerechtigkeit gilt der Capability Approach (CA) von Amartya Sen, Nobelpreisträger und Harvard-Professor für Ökonomie und Philosophie, als einer der einflussreichsten Beiträge moderner Gerechtigkeitstheorien. Trotz weitgehend positiver Resonanz der Scientific Community wird nach herrschender Meinung nur von einem »Ansatz« gesprochen. Das Buch widmet sich der Aufgabe, Amartya Sens CA begrifflich zu klären, zu systematisieren und inhaltlich weiterzuentwickeln, so dass er Schritt für Schritt an eine »vollwertige« Gerechtigkeitskonzeption herangeführt werden kann. Es ist einerseits als Standardwerk zu Sens politischer Philosophie zu lesen, andererseits vertieft der Autor den Ansatz hinsichtlich sozialer Gerechtigkeits- und globaler Entwicklungsfragen. Die hier vorgestellte Interpretation des CAs im Sinne der gerechtigkeitsnotwendigen Gewährleistung gleicher autonomer Freiheit liefert einen konstruktiven Brückenschlag zwischen der Philosophie Kants, Aristoteles' Tugendethik und der zeitgenössischen ökonomischen Theorie.

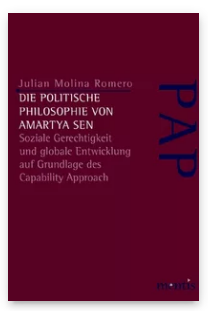

Pages: 338

Seiten

Language:

German

Subjects:

General,

Philosophy

Publisher: Brill | mentis

Series:

Perspektiven der Analytischen

Philosophie

E-Book (PDF)

Released online: 15 Jun 2016

ISBN: 978-3-

95743-913-0

List price

Paperback

Publication date: 15 Jun 2016

ISBN: 978-3-

95743-200-1

List price 
For more information see brill.com

Order information: Order online at brill.com +44330 333 0049 | customerservices@brill.com Submission information: brill.com/authors

Titles published by Brill | Fink, Brill | mentis or Brill | Schöningh: +49(o)715413279216| brill@brocom.de 